information across studies can be consolidated and translated into generalisable knowledge and practice more easily. ${ }^{1}$ Have they got it right?

The answer is both yes and no. The authors rightly say that this is work in progress and that improvements might be necessary. With this publication they aim to start a dialogue; they invite comments and feedback. Their decision to follow rigidly the 22 items of the CONSORT statement is a major limitation-this is not a case where one size fits all. Although I strongly endorse the suggestion that alternative ways, such as linked web pages, are needed to tackle fully the level of detail needed if an intervention is to be reproducible, ${ }^{9}$ I encourage a rethink and expansion to include named items relating to the development of interventions, and additional items for process and confounding variables. I would also redo item 8 (renamed assignment method), which attempts to capture the evaluation design used. This is the weakest part of the TREND statement, and it needs to be expanded to capture the whole range of evaluation designs; at present it is biased towards the evaluation of newly introduced interventions. I recommend an entry called evaluation design, including separate items for the two main dimensions ${ }^{4}$ : comparisons to be used (before and after, adopters $v$ non-adopters, intervention $v$ control and whether randomised or not,) and design of data collection (longitudinal, cross sectional, case-control).

However, this is an excellent and encouraging start and an important milestone in public health research. Having the TREND statement of agreed reporting standards for non-randomised designs increases their scientific credibility and draws attention to the scientific rigour involved in their conduct and design. It should challenge the prejudice that evaluation research is second rate and encourage more to do such research. We should look forward to its continuing development and evaluation.

Betty Kirkwood professor of epidemiology and international health

Nutrition and Public Health Intervention Research Unit, Department of Epidemiology and Population Health, London School of Hygiene and Tropical Medicine, London WC1E 7HT

(betty.kirkwood@lshtm.ac.uk)

Competing interests: None declared.

Des Jarlais DC, Lyles C, Crepaz N, the TREND Group. Improving the reporting quality of nonrandomized evaluations: the TRFND statement reporting quality of nonrandomize
Am J Public Health 2004:94:361-6.

2 Moher D, Schultz KF, Altman D. The CONSORT statement: revised recommendations for improving the quality of parallel-group randomised trials. JAMA 2001;272:122-4.

3 Smith PG. Evaluating interventions against tropical diseases. Int Epidemiol 1986;16:159-66.

Kirkwood BR, Cousens SN, Victora CG, de Zoysa I. Issues in the design and interpretation of studies to evaluate the impact of community-based interventions. Trop Med Int Health 1997;2:1022-9.

5 Black N. Why we need observational studies to evaluate the effectiveness of health care. $B M J 1996 ; 312: 1215-8$.

Victora CG, Habicht J-P, Bryce J. Evidence-based public health: moving beyond randomised trials. Am J Public Health 2004;94:400-5.

beyond randomised trials. Am J Public Health 2004;94:400-5.
Stephenson J, Imrie J. Why do we need randomised controlled trials to Stephenson J, Imrie J. Why do we need randomised cont
assess behavioural interventions. BMJ 1998;316:611-3.

Hall AJ, Inskip HM, Loik F, Day NE, O'Connor G, Bosch X, et al. The Gambia hepatitis intervention study. Cancer Res 1987;47:5782-7.

Campbell C, Fitzpatrick R, Haines A, Kinmouth AL, Sandercock P, Spiegelhalter D, et al. Framework for design and evaluation of complex interventions to improve health. BMJ 2000;321:694-6.

\title{
Pathogenesis and treatment of varicoceles
}

\author{
Controversy still surrounds surgical treatment
}

$\mathrm{T}$ The varicocele is an enigma in the treatment of male infertility. Despite over 30 years of evidence that repair of varicoceles results in improved fertility, ${ }^{1}$ the retrospective nature of most of these reports has led to controversy regarding the utility of treatment. This is compounded by the fact that not all varicoceles cause infertility. Varicocele is present in approximately $15 \%$ of men, and, although it is the most commonly diagnosed cause of male infertility, nearly two thirds of men with varicoceles remain fertile. The reason for this discrepancy remains unknown, although it is postulated that the cause of infertility is related to both temperature and time. ${ }^{2}$ The anatomical and physiological principles of the testicular vasculature and the evidence base regarding surgical treatment are outlined here.

The blood supply to the testis, as well as the resulting counter current heat exchange, results in cooler intratesticular temperatures compared with body temperature. ${ }^{3}$ Disruption of this system can result in hyperthermia of the testes. ${ }^{4}$ As the left side drains into a system with higher resistance, small venules may persist or open during embryogenesis. Testicular blood flow remains low before puberty, and therefore these veins do not become clinically apparent until adolescence when testicular blood flow increases, which explains the appearance of most varicoceles around puberty. ${ }^{5}$ Endo- infertility. Studies have shown altered function of the Leydig, Sertoli, and germ cells in men with notable varicoceles. ${ }^{6}$ Whether this is due to the increased intratesticular temperature or other factors is unknown.

Treatments vary from radiological ablation to surgical ligation of the varicocele, although most urologists reserve the radiological approach for the rare surgical failures. Numerous studies have examined various operative methods, attempting to show a difference in efficacy and outcome. Although most of these methods result in similar short term results, the open microsurgical methods tend to yield fewer long term complications, such as recurrences and hydroceles. $^{7}$ Although laparoscopic varix ligation was once touted as a minimally invasive method compared with open surgical repair, several authors have shown similar recovery rates, equal efficacy, fewer complications, and the advantage of not having to enter the abdomen. ${ }^{7}$ Most experts agree that only clinically apparent varicoceles should be treated. Although subclinical varicoceles (those identified by imaging studies only) may result in improvement in some seminal variables, evidence of efficacy is lacking regarding pregnancy rates. $^{8}$

A Cochrane review identified five randomised controlled trials that examined the outcomes in couples with male factor infertility and varicoceles and 
concluded that they did not show sufficient evidence regarding the treatment of varicoceles to warrant their repair. ${ }^{910}$ However, these studies were chosen for this review only because of to their status as randomised clinical trials; no evaluation of the methods was performed. On review of these trials, one examined only subclinical varicoceles, and three others exhibited methodological problems including the use of embolisation, high pregnancy rates in untreated couples $(25 \%$ in a one year period), and inherent selection bias in the study (many couples opted to pursue assisted reproductive technology rather than enter the study).

The one study that did show sizeable benefit was a randomised crossover design, in which over $50 \%$ of couples who underwent repair achieved pregnancy compared with $10 \%$ in the untreated couples. When the untreated couples were then crossed over and treated, another $50 \%$ became pregnant in the following year. However, men with severe oligospermia were excluded from this trial. ${ }^{11}$ Furthermore, preliminary data from an ongoing prospective randomised controlled trial have shown a fourfold increase in the spontaneous pregnancy rate in men with treated varicoceles compared with the control group. ${ }^{12}$ Although some of the reviewed studies had flaws, these findings raise the valid point of why most men with varicoceles are fertile, as well as why some infertile men with varicoceles do not improve after repair.

Although few randomised controlled trials show the benefit of treating varicocele related infertility, many non-randomised studies support this concept. ${ }^{12}$ A published review performed a careful analysis examining the issue of treatment outcome after varicocelectomy. Numerous studies were reviewed, most retrospective, and the following conclusions made. Most participants showed improvement in postoperative sperm density and motility. The natural pregnancy rates varied, but the overall average was $37 \%$, a clearly higher figure than any reported for non-treatment.
Although many of these studies suffer from the flaws of non-randomised trials, these results would be difficult to explain on the basis of chance alone.

Varicoceles continue to stimulate controversy among reproductive experts. Despite conflicting evidence from both randomised and non-randomised trials, clinical experience still favours the surgical treatment of clinical varicoceles in men with infertility. However, it is incumbent on fertility specialists to design and recruit participants (or patients) in randomised, properly controlled trials to reach a definitive conclusion.

Jay Sandlow associate professor

Department of Urology, Medical College of Wisconsin, $9200 \mathrm{~W}$. Wisconsin Avenue, Milwaukee, WI 53226 USA

(jsandlow@mail.mcw.edu )

Competing interests: None declared.

1 Dubin L, Amelar RD. Varicocele size and results of varicocelectomy in selected subfertile men with varicocele. Fertil Steril 1970;21:606-09.

2 Chehval MJ, Purcell MH. Deterioration of semen parameters over time in men with untreated varicocele: evidence of progressive testicular damage. Fertil Steril 1992;57:174-7.

3 Dahl EV, Herrick JF. A vascular mechanism for maintaining testicular temperature by counter-current exchange. Surg Gynecol Obstet 1959;108:697-705.

4 Goldstein M, Eid JF. Elevation of intratesticular and scrotal skin surface temperature in men with varicocele. J Urol 1989;142:743-5.

Braedel HU, Steffens J, Ziegler M, Polsky MS, Platt ML. A possible ontogenic etiology for idiopathic left varicocele. J Urol 1994;151:62-6.

6 Cayan S, Kadioglu A, Orhan I, Kandirali E, Tefekli A, Tellaloglu S. The effect of microsurgical varicocelectomy on serum follicle stimulating hormone, testosterone and free testosterone levels in infertile men with varicocele. BJU Int 1999;84:1046-9.

7 Fretz PC, Sandlow JI. Varicocele: current concepts in pathophysiology, diagnosis, and treatment. Urol Clin North Am 2002;29:921-37.

8 Jarow JP, Ogle SR, Eskew LA. Seminal improvement following repair of ultrasound detected subclinical varicoceles. J Urol 1996;155:1287-90.

Evers JL, Collins JA, Vandekerckhove P. Surgery or embolisation for varicocele in subfertile men. Cochrane Database Syst Rev 2001:1:CD000479.

10 Evers JL, Collins JA. Assessment of efficacy of varicocele repair for male subfertility: a systematic review. Lancet 2003:361:1849-52.

11 Madgar I, Weissenberg R, Lunenfeld B, Karasik A, Goldwasser B. Controlled trial of high spermatic vein ligation for varicocele in infertile men. Fertil Steril 1995;63:120-4

12 Schlesinger MH, Wilets IF, Nagler HM. Treatment outcome after varicocelectomy. A critical analysis. Urol Clin North Am 1994;21:517-29.

\section{Management of acute pancreatitis}

\section{Role of antibiotics remains controversial}

A cute pancreatitis is a common surgical emergency. The incidence in the United Kingdom has been reported to be as high as 38 per 100000 per year and increasing. Around 25\% of patients develop severe or life threatening complications, requiring support in high dependency or intensive care units. Mortality has fallen from 25-30\%, 30 years ago, but has remained at $6-10 \%$ for most of the past two decades. ${ }^{1}$ The initial improvement did not occur because of any specific treatment for acute pancreatitis but because of improved supportive treatment, especially advances in critical care. This supportive treatment may include a role for prophylaxis with antibiotics in acute pancreatitis.

The rationale for prophylaxis with antibiotics is based on the fact that mortality for infected pancreatic necrosis is higher than that for sterile necrosis, and a potential window of opportunity exists during the first to third weeks for prevention of infection by giving pro- phylactic antibiotics. A recent Cochrane review supports this view. ${ }^{2}$ Despite this, the role of antibiotic prophylaxis in acute pancreatitis remains controversial. Questions remain unanswered as to choice and duration of treatment. Risks exist of encouraging antibacterial resistance and opportunistic fungal infections. Moreover, preliminary reports of two new trials do not confirm the benefits of prophylaxis with antibiotics.

The practice of antibiotic prophylaxis in acute pancreatitis is widespread. A survey of 1103 surgeons in the United Kingdom and Ireland showed that prophylactic treatment with antibiotics was used by $88 \%$ of 528 responding surgeons, of whom $24 \%$ used it in all patients. ${ }^{3}$ Mild acute pancreatitis is a short lived and self limiting disease. A policy of giving antibiotics to all patients with acute pancreatitis can therefore not be supported. The task is to identify which subgroup of patients will benefit from prophylactic antibiotics during the course of an attack of acute pancreatitis. 